$\xi=-1$

\title{
Biodiversity Information System for Management of Medicinal Plants Data Tropical Rainforest Borneo
}

\author{
Joan Angelina Widians ${ }^{1}$, Masna Wati², Andi Tejawati ${ }^{3}$, Edy Budiman ${ }^{4 *}$ \\ ${ }^{1,2,3,4}$ Dept. of Informatics Engineering \\ Universitas Mulawarman, Samarinda 75119, East Kalimantan - Indonesia \\ *Corresponding author E-mail: edy.budiman@ieee.org
}

\begin{abstract}
This paper is an effort to inform about the potential of medicinal plants in forest areas in the Borneo region. Given the high rate of destruction of rainforests on Borneo, literacy and conservation efforts of medicinal plants that are part of the forest ecosystem are important. This study developed BBIS, namely Borneo Biodiversity Information System. BBIS is the development of computer-based technology for managing information on Borneo's natural resource biodiversity in order to improve the knowledge management of medicinal plants. In particular, development of the Biodiversity Information System which can be used as an exploring media for exchange information society on Borneo's biodiversity. Profile biodiversity complete and well managed will be a reference in the process of monitoring the use of biological diversity, strategies, and plans related to the biodiversity of the medicinal plants on Borneo Island.
\end{abstract}

Keywords: Biodiversity; Medicinal Plants; Tropical Rainforest; Borneo.

\section{Introduction}

Borneo is the third largest island in the world known as one of the two centers of world plant diversity. Kalimantan is part of the island of Borneo located in the territory of the Unitary State of the Republic of Indonesia [1]. The Kalimantan region includes five provinces, i.e. West Kalimantan, Central Kalimantan, South Kalimantan, East Kalimantan and North Kalimantan. This $73 \%$ of the area of the island of Borneo) [2].

Biodiversity data in Borneo is still quite difficult in terms of access, information disclosure does not always encourage this data so that it can be accessed freely and easily by the public. Almost all sites related to biodiversity data are quite difficult to provide complete data, data distribution is still very minimal, others are still in the research desk and not published, each region only collects biodiversity data according to their individual needs and with data formats which do not support interoperability and can only be read by certain software.

One product of Borneo forest plants is medicinal plants. The potential of medicinal plants in the forest area in Borneo is quite diverse, some of which have been utilized by the community around the area as well as untapped. From the study [3] of various studies conducted in the Borneo forest area, it can be seen that this area has the potential for diverse medicinal plants. The potential recorded at this time has not shown the potential of Borneo medicinal plants as a whole, but can describe the potential of medicinal plants in a variety of certain forest areas. The potential of this medicinal plant is spread in various forest areas both conservation areas such as national parks, research forest areas, protected forests and other forest areas.

The types of medicinal plants that have been successfully identified and documented through various studies are types that have traditionally been used by local communities. In fact, several stud- ies have examined the ethnobotany of certain tribes in Kalimantan, including the use of medicinal plants for medicinal purposes. There is a tendency that the types of medicinal plants in the forest area in Borneo are types that are used by tribes that inhabit the area. In terms of utilization, various types of medicinal plants in the Borneo forest have their own efficacy and have a large potential to be developed.

Many researchers at Mulawarman University and Indonesia have conducted research into the potential of Bornean forest medicinal plant biodiversity. But most of the research results are still stored in the form of papers/books/books. There is still a very little amount of data stored in digital systems.

With the large percentage of non-digital documents, data and information about biodiversity are difficult to access. This condition will cause information and knowledge not to be disseminated properly, as a result, it will threaten the sustainability of living natural resources.

Information on medicinal plant biodiversity is very important for scientific studies / research, education and decision-making. In natural resource management, biodiversity information is needed to maintain the continued use of species, explore biological potential and monitor species and ecology, make policies, and develop biotechnology innovations. Given the importance of the role of information on the body, it is necessary to develop a computerbased technology that can manage data, information and knowledge of biodiversity properly and efficiently so that it can be used for exploration, analysis, synthesis, and interpretation of potential biodiversity riches.

Related to the above, require effort for data collection of the ethnomedicine, and integrate into a database management system so that the sustainability of medicinal plant biodiversity in Borneo can be preserved.

This study developed BBIS, namely Borneo Biodiversity Information System. BBIS is the development of computer-based technology for managing information on Borneo's natural resource 
biodiversity in order to improve the knowledge management of medicinal plants. The paper aims to develop a Biodiversity Information System (BIS) of the medicinal plant from tropical rainforest Borneo based on International Code Botany Nomenclature (ICBN), while its specific objectives i.e.: Making software products in the form of medicinal biodiversity information systems in an effort to support a sustainable biodiversity monitoring system. Collecting data on medicinal plants based on information and traditional knowledge of medicinal plants from indigenous tribes in Borneo and as an effort to digitally preservation the culture and local wisdom of indigenous people so as not to erode, and until now, there are still many types of medicinal plants that have not been studied and the benefits are unknown.

\section{Methodology}

\subsection{Data, Sources, and Collection Methods}

The data on medicinal plants are collected from observing agencies, conservation institutions in the Kalimantan region, main book sources from [4], and [5] and several results of ethnobotanical study medicinal plants. The representation of the data model for taxonomic information refers to the International Code Nomenclature for algae, fungi, and plants [6].

\subsection{Nomenclature of Medicinal Plants}

According to the International Code of Nomenclature [6], there are seven general classification categories defined in plants, such as the example classification for "eleutherine" species [7] shown in Table 1.

Table 1: An example of the scientific classification of plants for "eleutherine Palmifolia"

\begin{tabular}{|l|l|l|}
\hline Kingdom & Plantae & Plant \\
\hline Division & tracheophyta & vascular plants \\
\hline Class & liliopsida & monokotiledon \\
\hline Order & asparagales & herbaceous plants \\
\hline Family & iridaceae & flowering plants \\
\hline Genus & eleutherine herb. & herb. flower \\
\hline species & e. palmifolia (1.) merr & bawang dayak \\
\hline
\end{tabular}

\subsection{Software Development Models}

In principle, software development methods aim to help produce quality software. Software development methods provide techniques for building software related to a broad range of tasks involving requirements analysis, program construction, design, application, testing, and maintenance. The software development model uses a prototype approach [8], the Prototype model implements several parts of the function of the actual software. In this way the user will get an overview of the program that will be produced, so that it can describe in more detail their needs. As for the stages of development of this model is presented in Fig. 1.

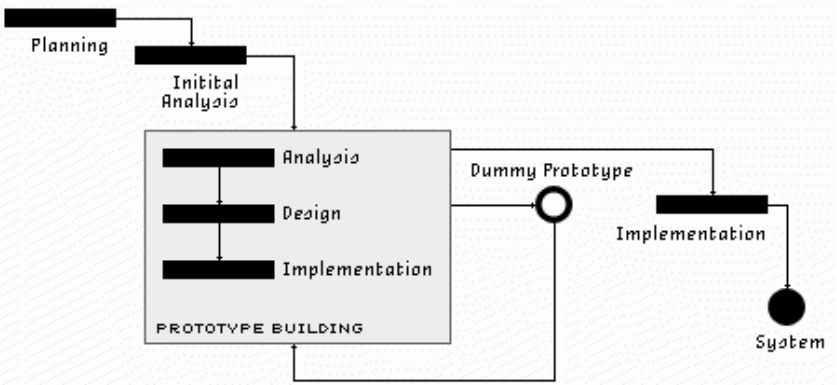

Fig. 1: Throw-away prototyping model [9]

\subsection{Software Analysis and Design}

The general modeling language used to specify, visualize, construct and document artifacts from the software system uses the Unified Modeling Language (UML). UML is used in modeling an object-based system [10].

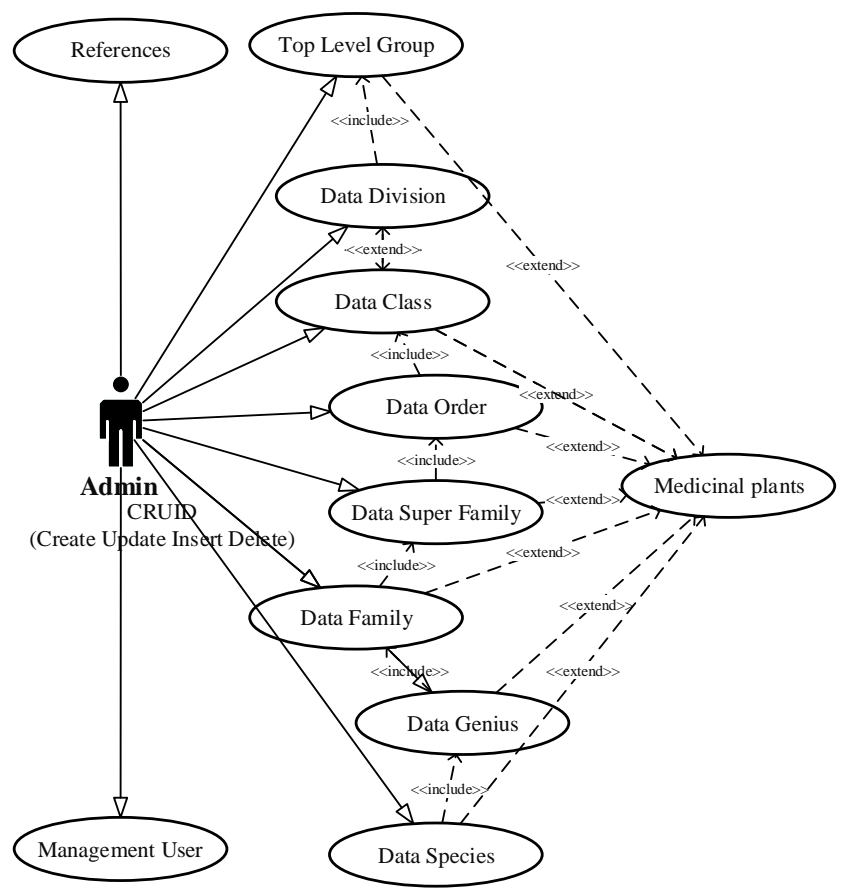

Fig. 2: Use case diagram for administrator

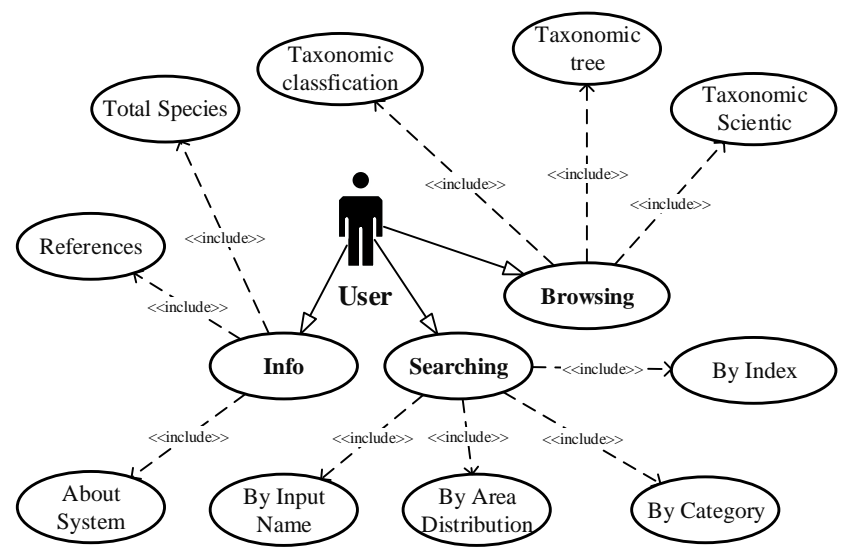

Fig. 3: Use case diagram for user

Fig. 2 and Fig. 3 Use case diagrams for system user and ad$\min$.

\subsection{Three-tier Architecture}

The development of BIS can be implemented with various approaches and technologies. Scale enterprise applications such as BIS was developed with an object-oriented approach using a three-tier-architecture i.e. client environment, network-internet, and database layer [11]. 


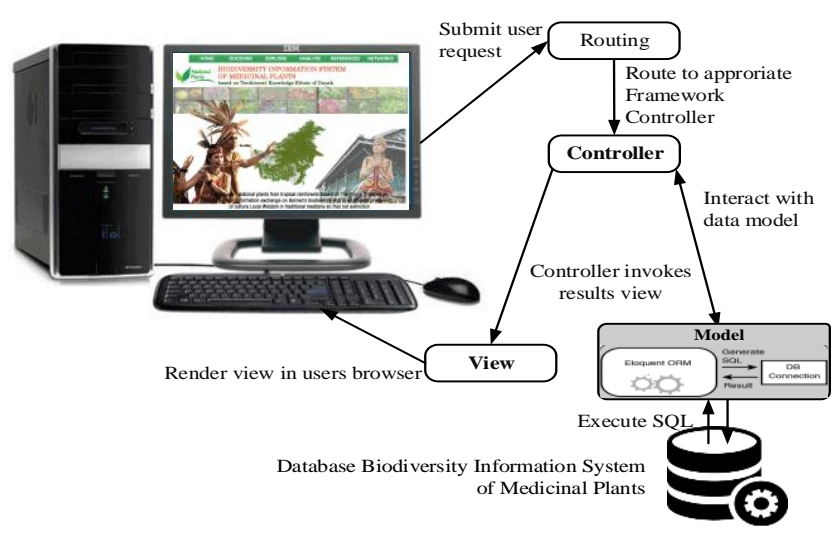

Fig. 4: Three tier architecture for BBIS medicinal plants

In Fig. 4 as an overview of the Borneo Biodiversity System Information with Model-View-Controller (MVC) and interaction with the database [12-20].

\section{Results and Discussion}

\subsection{System Implementation}

The results of BBIS medicinal plants development can be seen at the URL address: https: //borneodiversity.org/index/medicinal, then the main page interface is presented in Fig. 5 .

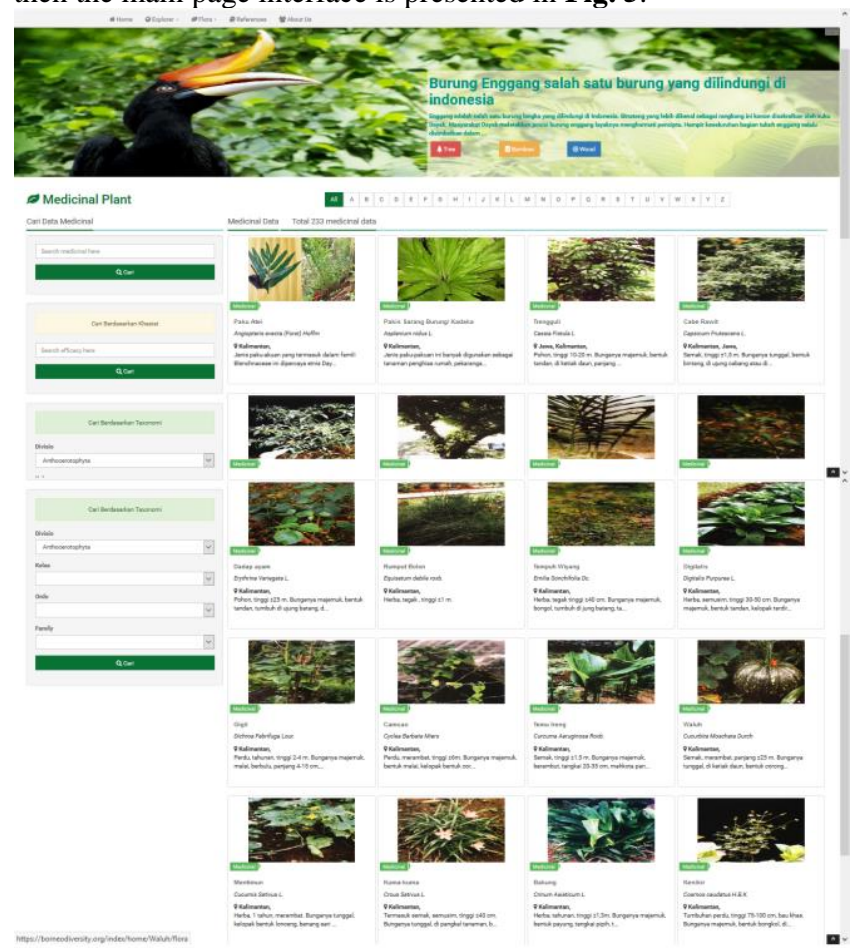

Fig. 5. Homepage BBISystem of Medicinal plants

Based on the results of exploration and initial inventory conducted from various research locations spread in East Kalimantan, Central Kalimantan, East Kalimantan, and South Kalimantan, medicinal plant species used by ethnic groups were recorded in Kalimantan. Found 233 species of medicinal plants used by indigenous tribes of Borneo, Paser Dayak and Buro Mato Dayak in the Tanjung Pinang area, Upper Rantau area and Muara Andeh area in Paser District, East Kalimantan. In the Right Menamang and Menamang Regions, 85 species were used by the Kutai ethnic group in the East Kalimantan Province of Kutai Kartanegara Regency. While in South Kalimantan Province there were 92 types of ethnic Banjar and Dayak Meratus in Mayanau, Awayan, and Japan in Balangan Regency. A total of 56 types of medicinal plants are used by ethnic Manyan Dayaks in the Ampah and surrounding areas in East Barito Regency, Central Kalimantan Province.

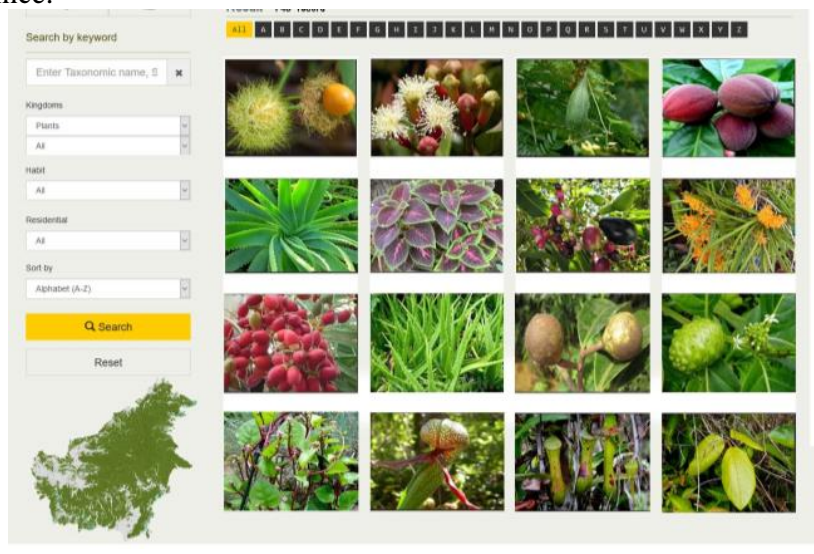

Fig. 6: Menu browse taxonomic classification

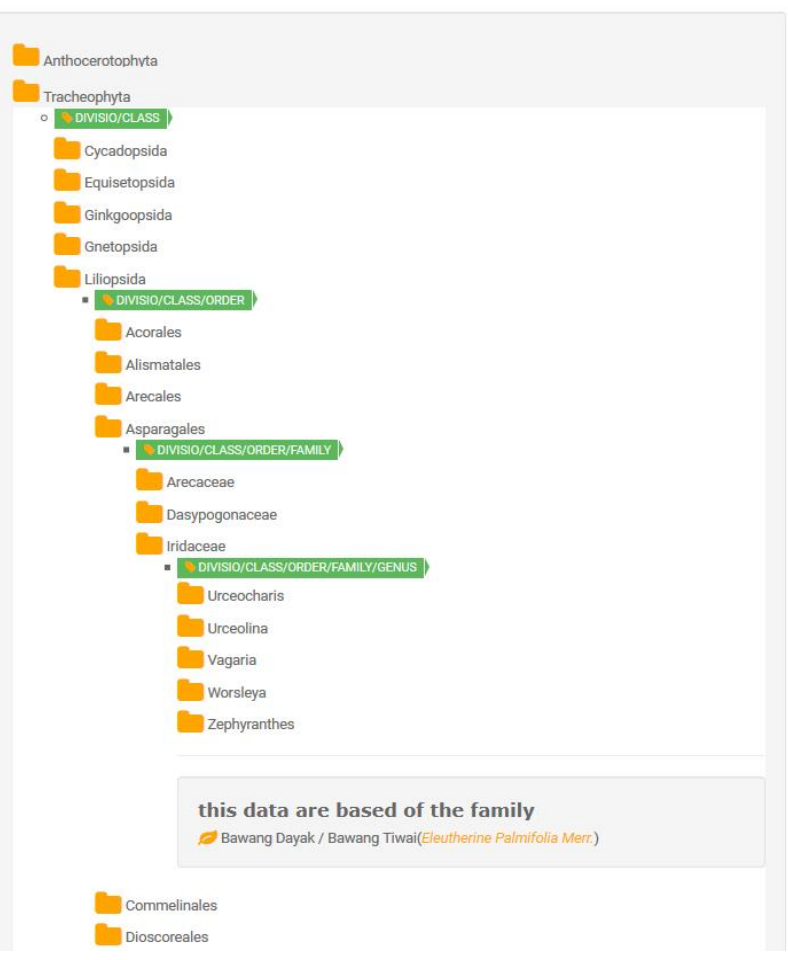

Fig. 7: Menu browse Tree diagram

Fig. 6 Classification of medicinal plant plants is arranged based on taxon-taxon regularly following a hierarchy. Taxes found in lower taxon (category) levels have more in common than taxon contained in taxon levels (categories) in them. Tree diagrams provide an overview of the phylogenetic relationships among subgroups. For example, the tree diagram of the type species "Eleutherine" presented in Fig. 7. 


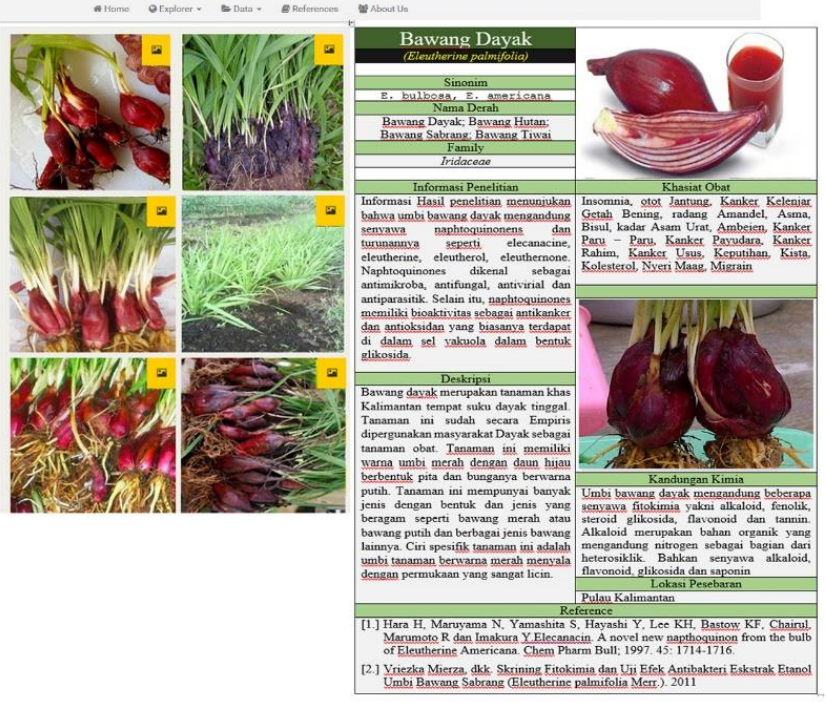

Fig. 8. Menu searching a species "eleutherine"

For document searching of medicinal plant, we provide several models of the search interface menu i.e. in the Fig. 8, user input keyword and press search button by all names, searching by category, by area distributions or habit, by indexing, etc. The result of searching for "eleutherine", which a displays general information on the species, taxonomic data and photo galleries.

\subsection{Utilization of Efficacious Medicinal Forest Plants}

The results of research from medicinal plant data show that the use of medicinal plants, especially forest plants, still uses simple processing methods, such as boiling, soaking, chewing, squeezing and pounding or pounding. There are plants that are used in traditional medicine that go through the process before being used, some of which are directly used without going through the processing process. Ways to preserve raw materials from Efficacious Medicinal Plants Medicines still use conventional methods by drying or aerating. The most widely used parts of the drug vary depending on the extraction system and the amount taken. Taking these medicinal ingredients can cause growth and regeneration of plants to be disrupted. From the results of data collection, parts of plants used as medicinal ingredients can be grouped into 4 (four) groups, i.e.: roots, leaves, skins/stems, etc. (Fruit, sap, flowers, seeds, and fruit peels, water stems, tubers) The part of the plant used is shown in Fig. 9.

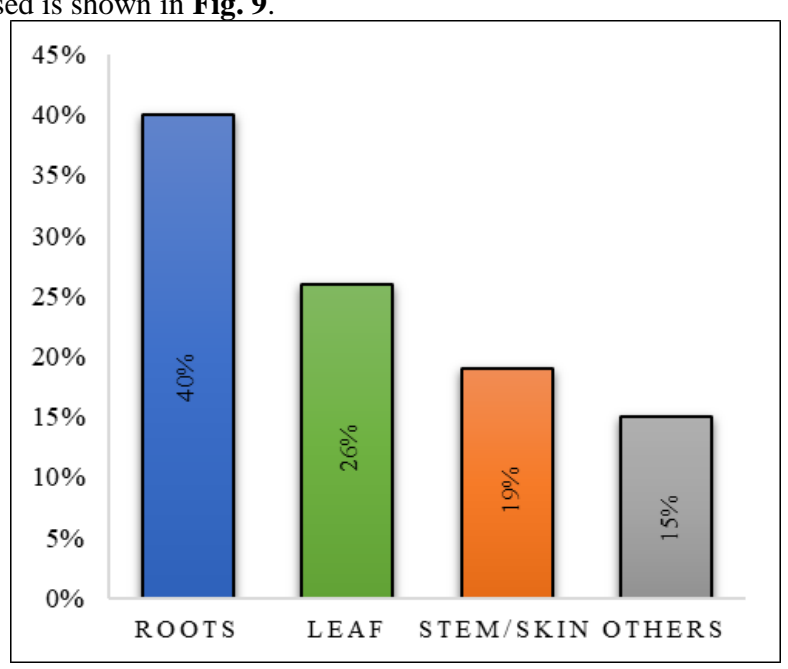

Fig. 9. Parts of plants used in medicine

In Fig. 9, roots are part of the most widely used plant in traditional medicine. In terms of conservation, the use of roots as medicinal raw materials will disrupt the survival of plants and possibly cause death. The use of roots in medicine tends to damage the preservation of the efficacious species of forest plants. In contrast to the use of medicinal leaves of medicinal plants, it must be accompanied by conservation and cultivation efforts for the preservation of the nutritious medicinal plants of Borneo.

\subsection{Web Performance Testing}

The more technology develops, the faster the use of websites as a medium of communication, through media sites, information is easily presented and accessed. However, errors in website development, both in terms of programming and content, will affect the performance of web and network servers. Therefore, application developers need to use tools to assess the performance of web applications, so as to reduce errors or lacks. The analysis and calculation of efficiency testing of website:borneodiversity.org using GT-Metrix tool [21-23], then the Grade and score as shown in Fig. 10 for recommendation of Pagespeed and recommendation of YSlow. The results of the performance tests for YSlow are presented in Fig. 11.

\section{PageSpeed}

RECOMMENDATION

- Serve scaled images

- Optimize images

- Leverage browser caching

- Enable gzip compression

- Defer parsing of JavaScript

- Minify css

- Minify HTML

- Specify a character set early

- Minify JavaScript

- Specify image dimensions

- Avoid bad requests

- Avoid landing page redirects

- Enable Keep-Alive

- Inline small css

- Inline small Javascript

- Minimize redirects

- Minimize request size

- Optimize the order of styles and scripts

- Put css in the document head

- Serve resources from a consistent UR

- Specify a cache validator

- Specify a Vary: Accept-Encoding header

- Combine images using css sprites

- Avoid css @import

- Prefer asynchronous resources

- Avoid a character set in the meta tag

Remove query strings from static resources

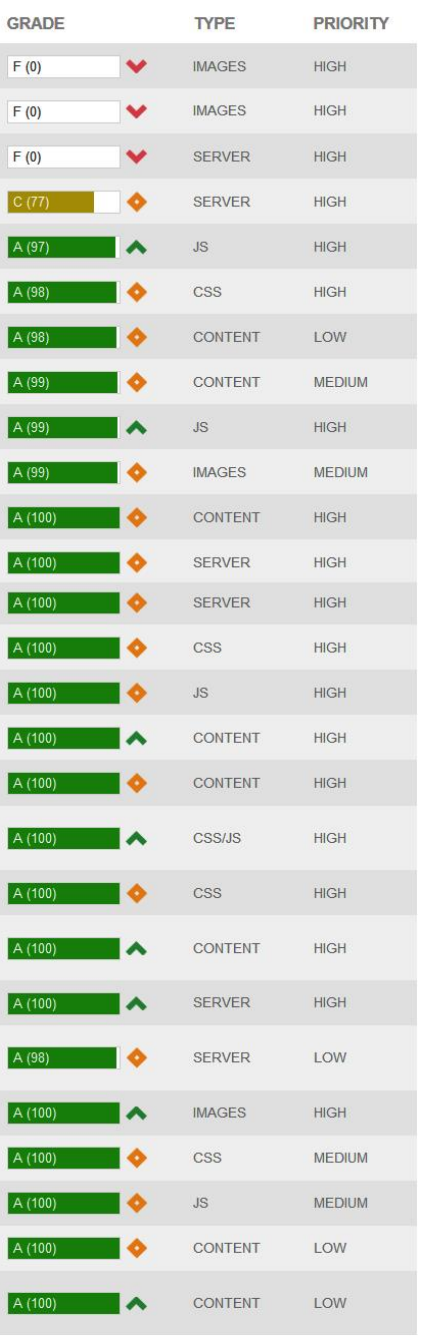

Fig. 10: Recommendation of PageSpeed
In principle, the page loading speed of a website will improve the user experience in accessing information.

Fig. 10 is the result of website analysis based on recommendations from PageSpeed using the GTMetrix web performance tool. The results of the analysis indicate that there are Recommendations that obtain a Grade worth 0, i.e: Serve scaled images F (0), Optimize images $\mathrm{F}(0)$, and Leverage browser caching $\mathrm{F}(0)$, and Enable GZIP compression with Grade score C (77). 


\begin{tabular}{|c|c|c|c|c|}
\hline PageSpeed & & & & \\
\hline RECOMMENDATION & GRADE & & TYPE & PRIORITY \\
\hline Add Expires headers & $F(0)$ & $v$ & SERVER & HIGH \\
\hline - Use a Content Delivery Network (CDN) & $F(0)$ & $v$ & SERVER & MEDIUM \\
\hline Make fewer HTTP requests & $D(60)$ & $\wedge$ & CONTENT & HIGH \\
\hline Use cookie-free domains & $F(0)$ & $\checkmark$ & COOKIE & Low \\
\hline Compress components with gzip & $B(89)$ & A & SERVER & HIGH \\
\hline - Minify JavaScript and CsS & $A(90)$ & 1へ & css/ss & MEDIUM \\
\hline - Reduce DNS lookups & $\mathrm{A}(95)$ & Iへ & CONTENT & Low \\
\hline Avoid URL redirects & $A(100)$ & 1へ & CONTENT & MEDIUM \\
\hline - Make AJAX cacheable & $A(100)$ & ४ & Js & MEDIUM \\
\hline Remove duplicate JavaScript and CSS & $A(100)$ & 1• & css/Js & MEDIUM \\
\hline - Avoid AlphalmageLoader filter & $A(100)$ & $1 \bullet$ & css & MEDIUM \\
\hline - Avoid HTTP 404 (Not Found) error & $A(100)$ & 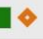 & CONTENT & MEDIUM \\
\hline Reduce the number of DOM elements & $A(100)$ & ヘ & CONTENT & Low \\
\hline - Use GET for AJAX requests & $A(100)$ & $1 \bullet$ & JS & Low \\
\hline - Avoid CsS expressions & $A(100)$ & $1 \bullet$ & css & Low \\
\hline - Reduce cookie size & $A(100)$ & 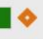 & COOKIE & Low \\
\hline Make favicon small and cacheable & $A(100)$ & $\bullet$ & IMAGES & Low \\
\hline - Configure entity tags (ETags) & $A(100)$ & 1へ & SERVER & Low \\
\hline Make JavaScript and csS external & (n/a) & & css/ss & MEDIUM \\
\hline
\end{tabular}

Fig. 11: Recommendation of YSlow

For the results of performance analysis according to recommendations from YSlow, In Fig. 11 shows that Recommendations: Add Expires headers Grade F (0), Use a Content Delivery Network $(\mathrm{CDN})$ is F (0), Make fewer HTTP requests is D (60), and Use cookie-free domains is $\mathrm{F}(0)$.

\section{Evaluation:}

- Generally the problem with the results of a web performance analysis is the lack of assessment achieved in the ADD Expired Header recommendation section. One thing that must be understood is that if Leverage browser Expires Headers are closely related to a web page such as images, CSS, Java Script, and so on. So, when reopening the same web page, the webpage will open faster. Because files that were originally downloaded must now be stored in the storage media. The main function of Leverage browser caching itself is to set expires in static HTTPS headers. besides also giving commands to the browser to load the Source Code that was previously downloaded in the storage media, and the function of the Caching is to set the length of file storage that was downloaded when opening.

- Basically, Serve scaled images is to call or display images according to their dimensions, meaning that each image source is adjusted to the size of the image displayed. For Optimize images problems means optimizing image size so that large image file sizes can be smaller. Smaller images will certainly be faster than large images. It is recommended to optimize the image as much as possible.

- Content Delivery Network (CDN) is one of the technologies to fulfill these two factors. By placing multiple servers in different locations, CDN will be able to reduce access times much faster than normal access times. When a user or user sends a web page request to a web server, the web page will be sent to the main server, even though the main server is located throughout the country from the user's position. But by using CDN technology, when a user or user sends a web page request to a web server, the web page will be sent to the server closest to the user's location. But because CDN is digital technology, it means that CDN is vulnerable to cyber-ware problems that have spread in various countries.

\section{Conclusion}

The level of biodiversity of medicinal plants high in the forests of Borneo is currently experiencing a lot of pressure due to excessive use and use of forest products beyond its carrying capacity. The potential value of future beings disappears. Regarding this matter, it is necessary to follow up on data handling and monitoring activities so that the sustainability of medicinal plant biodiversity is maintained and sustainable.

Development of the Biodiversity Information System of the tropical rain forest Borneo as a media for management data and information on medicinal plants is the first step in efforts to disseminate public literacy, the potential use of Kalimantan medicinal plants by inventorying and documenting knowledge. Concerned about the increasing number of Bornean medicinal plants that are extinct due to our ignorance of the benefits and roles in life, especially the potential that has a contribution in public health.

\section{Acknowledgement}

The project is funded by the 2016-2019 Islamic Development Bank Loan Project in collaboration with Mulawarman University. We thanks to Provincial Forestry Office of East Borneo, Research Center for Dipterokarpa, Technology Research Institute for Conservation of Natural Resources (BALITEK KSDA) Samboja, Research Institute for Spices and Medicinal Plants (BALITTRO), Research and Development Agency Department of Health, Kutai National Park (KNP) Bontang, which have been help and support in research data collection.

\section{References}

[1] https://www.worldatlas.com/articles/which-countries-share-theisland-of-borneo.html

[2] M. Fatawi, and T. Mori. "Description of forests and forestry in East Kalimantan." Rainforest ecosystems of East Kalimantan. Springer, Tokyo, 2000. 3-12.

[3] Noorhidayah, N., 2006. Potensi dan Keanekaragaman Tumbuhan Obat di Hutan Kalimantan dan Upaya Konservasinya. Jurnal Analisis Kebijakan Kehutanan, 3(2), pp.95-107.

[4] Noorcahyati, Tumbuhan Berkhasiat Obat Etnis Asli Kalimantan, Balai Penelitian Teknologi Konservasi Sumber Daya Alam Kementerian Kehutanan, 2012.

[5] Kissinger, K., Zuhud, E.A., Darusman, L.K. and Siregar, I.Z., Keanekaragaman Jenis Tumbuhan Obat dari Hutan Kerangas. Jurnal Hutan Tropis, vol. 1(1), 2016.

[6] J. McNeill, F. R. Barrie, W. R. Buck, V. Demoulin, W. Greuter, D. L. Hawksworth, P. S. Herendeen, S. Knapp, K. Marhold, J. Prado, and W. F. Prud'homme Van Reine.: In International Code of Nomenclature for algae, fungi, and plants (Melbourne Code). Regnum vegetabile, Des, 2012, p.154.

[7] N. C. R. Yuswi, Ekstraksi Antioksidan Bawang Dayak (Eleutherine Palmifolia) Dengan Metode Ultrasonic Bath (Kajian Jenis Pelarut dan Lama Ekstraksi). Jurnal Pangan dan Agroindustri, vol. 5(1), 2017.

[8] Everett, G.D. and McLeod Jr, R., Software testing: testing across the entire software development life cycle. John Wiley \& Sons, 2007.

[9] https://melsatar.blog/2012/03/15/software-development-life-cyclemodels-and-methodologies/

[10] M. Principe, and Y. David.: A Web Application Using MVC Framework," in Proceedings of the International Conference on eLearning, e-Business, Enterprise Information Systems, and eGovernment (EEE), p. 10. The Steering Committee of the World Congress in Computer Science, Computer Engineering and Applied Computing (WorldComp), 2015.

A. Dennis, B. H. Wixom, D. Tegarden.: Systems analysis and design: An object-oriented approach with UML. John Wiley \& Sons, March, 2015.

[11] E. Budiman, M. Jamil, U. Hairah, H. Jati and Rosmasari, "Eloquent object relational mapping models for biodiversity information system," 2017 4th International Conference on Computer Applications 
and Information Processing Technology (CAIPT), Kuta Bali, 2017, pp. 1-5. doi: 10.1109/CAIPT.2017.8320662

[12] Dengen, N., Budiman, E., Widians, J.A., Wati, M., Hairah, U., and Ugiarto, M., Biodiversity information system: Tropical rainforest borneo and traditional knowledge ethnic of dayak. Journal of Telecommunication, Electronic and Computer Engineering, vol. 10. No 1-9, 2018, pp. 59-64.

[13] U. Hairah, A. Tejawati, E. Budiman and F. Agus, "Borneo biodiversity: Exploring endemic tree species and wood characteristics," 2017 3rd International Conference on Science in Information Technology (ICSITech), Bandung, 2017, pp. 435-440. doi: 10.1109/ICSITech.2017.8257152.

[14] E. Budiman and S. N. Alam, "Database: Taxonomy of plants Nomenclature for borneo biodiversity information system," $2017 \mathrm{Sec}$ ond International Conference on Informatics and Computing (ICIC), Jayapura, 2017, pp. 1-6.

[15] doi: 10.1109/IAC.2017.8280642

[16] Haeruddin, H. Johan, U. Hairah and E. Budiman, "Ethnobotany database: Exploring diversity medicinal plants of Dayak tribe Borneo," 2017 4th International Conference on Electrical Engineering, Computer Science and Informatics (EECSI), Yogyakarta, 2017, pp 1-6. doi: 10.1109/EECSI.2017.8239094

[17] Budiman. E, Hairah. U, Haeruddin, Tejawati. A, Darmawan. S and Wahyuni. S, "Biodiversity Information System of Medicinal Plants from Tropical Rainforest Borneo Based on Traditional Knowledge Ethnic of Dayak," Advanced Science Letters, Vol. 24 (1), November 2018, pp. 8668-8673(6). American Scientific Publishers.

[18] doi: 10.1166/asl.2018.12321.

[19] E. Budiman, M. Wati, J. A. Widians, N. Puspitasari, M. B. Firdaus and F. Alameka, "ISO/IEC 9126 Quality Model for Evaluation of Student Academic Portal," 2018 5th International Conference on Electrical Engineering, Computer Science and Informatics (EECSI), Malang, 2018, pp. 499-504.

[20] E. Budiman, N. Puspitasari, S. N. Alam, M. A. Akbar, Haeruddin, F. Alameka, "Performance Analysis of the Resource Loading Time for Borneo Biodiversity Information System," 2018 The Third International Conference on Informatics and Computing (ICIC), Palembang, pp. 1-6.

[21] E. Budiman, Haeruddin and A. Tejawati, "Efficiency and Reliability Performance's of the Bioinformatics Resource Portal," 2018 5th International Conference on Electrical Engineering, Computer Science and Informatics (EECSI), Malang, 2018, pp. 493-498

[22] GTmetrix, Homepage: https://gtmetrix.com/

[23] YSlow, Homepage: http://yslow.org/ruleset-matrix/

[24] N. Puspitasari and E. Budiman, "Evaluation of Borneo's Biodiversity Information System," 2018 9th Electrical Power, Electronics, Communications, Controls, and Informatics Seminar (EECCIS) Malang, 2018, pp 